
Off-Board EV Battery Chargers"

IEEE IECON Industrial Electronics Conference, Lisbon, Portugal, Oct. 2019.

This material is posted here with permission of the IEEE. Such permission of the IEEE does not in any way imply IEEE endorsement of any of Group of Energy and Power Electronics, University of Minho, products or services. Internal or personal use of this material is permitted. However, permission to reprint/republish this material for advertising or promotional purposes or for creating new collective works for resale or redistribution must be obtained from the IEEE by writing to pubs-permissions@ieee.org. By choosing to view this document, you agree to all provisions of the copyright laws protecting it.

(C) 2014 IEEE 


\section{Experimental Validation of a Bidirectional Three-Level dc-dc Converter for On-Board or Off-Board EV Battery Chargers}

\author{
Vitor Monteiro \\ Centro ALGORITMI \\ University of Minho \\ Guimaraes, Portugal \\ vmonteiro@dei.uminho.pt \\ Jose A. Afonso \\ CMEMS-UMinho Center \\ University of Minho \\ Guimaraes, Portugal \\ jose.afonso@dei.uminho.pt
}

\author{
Joao C. Ferreira \\ INOV INESC Inovação \\ ISCTE-IUL \\ Lisboa, Portugal \\ jcafa@iscte-iul.pt \\ Carlos Couto \\ Centro ALGORITMI \\ University of Minho \\ Guimaraes, Portugal \\ ccouto@dei.uminho.pt
}

\author{
Andres A. Nogueiras Melendez \\ Departamento de Tecnología \\ Electrónica - University of Vigo \\ Vigo, Spain \\ aaugusto@uvigo.es
}

\author{
Joao L. Afonso \\ Centro ALGORITMI \\ University of Minho \\ Guimaraes, Portugal \\ jla@dei.uminho.pt
}

\begin{abstract}
This paper presents a bidirectional three-level (B3L) dc-de converter for electric mobility applications, namely for EV battery chargers (structures of on-board or off-board). As shown throughout the paper, the B3L dc-dc converter is only part of the on-board or off-board chargers, and may also be framed in galvanic isolated or non-isolated electrical systems. As main differentiating factor, according to the output voltage value, it can operate with three-levels, allowing to reduce the voltage applied to each switching device. Besides, it operates with the output controlled current with a frequency that is double of the switching frequency of each device. Taking into account the advantages of the B3L dc-dc converter, a comparison with a conventional converter is established. The adopted PWM strategy is defined according to the current control technique. The experimental validation is performed using two prototypes: an on-board charger and an off-board charger. The obtained results allow verifying the claimed innovative characteristics and advantages of the B3L dc-dc converter.
\end{abstract}

Keywords-Three-Level Converter, dc-dc Converter, Electric Vehicle, Smart Grids, On-Board Charger, Off-Board Charger.

\section{INTRODUCTION}

As widely reported, the topic of sustainable electrical energy is absolutely relevant for upcoming generations. The smart grids appear as a contribution to support these topics [1][2][3]. In terms of key technologies requiring power electronics equipment, the most predominant are electric mobility (e.g., pure battery vehicles or hybrid vehicles), renewable energy sources (e.g., distributed generation supported by solar photovoltaic panels), and energy storage systems (e.g., for matching the integration of renewables with electric mobility and for demand response programs). Although the relevance and convergence of these three vectors, this paper only focus on power electronics for electric mobility integration. The state-of-the-art about the diverse technologies of vehicles for the electric mobility is offered in [4], [5], and in [6], where the distinct architectures of each technology are scrutinized in [7]. Considering the smart grid outlook, a survey concerning electric mobility is analyzed and accessible in [8], and the integration from the power system perspective is revised in [9]. The electric mobility dissemination and incorporation in scenarios of microgrids, as a boost factor for smart grids, is explored in [10] and in [11]. The user perspective in terms of an optimized electric mobility integration, concerning the battery charging process, is studied in [12]. A cooperative combination of electric mobility and renewables for the sustainability of the energy and transports sectors is considered in [13]. A flexible control between electric mobility and renewables is proposed in [14] as a perspective of reducing the greenhouses gases emissions. Other relevant contributions of the electric mobility cooperation for a sustainable electrical energy is presented in [15] for power quality improvement, in [16] for an economic dispatch model, in [17] for minimizing the costs in charging stations, and in [18] for a demand-side managing of electric mobility, renewables and energy storage. Associated with the electric mobility, technological challenges are always present for the integration of charging systems based on a direct interface with the power grid, either through on-board or through off-board systems [19][20]. As the batteries (dc) cannot be directly connected to the power grid (ac), the charging systems employ ac-dc and dc-dc power stages with closed-loop control, either through current or through voltage [21]. In this perspective, in a view of meeting the needs of the next generation of electric mobility, more integrated with other technologies (e.g., renewables) and more aligned with the smart grids, the design of the dc-dc power stage will be a differentiator factor. The need to adopt more sophisticated dc-dc power stages is also rooted in the convergence for dc-grids, as well as in the integration of multiple technologies sharing the same dc-link and using only an ac-dc converter responsible for the ac-grid interface. Some of these examples are presented in [22], [23], [24], [25], [26], and [27]. In this chaining of new perspectives for the future smart grids, this paper presents a bidirectional three-level (B3L) dc-dc converter, when used as a power stage in on-board or off-board EV chargers [28]. In the scope of this paper, the main highlights as contributions of the B3L dc-dc converter for on-board or off-board EV chargers are: (i) The B3L dc-dc converter operates with the variables (e.g., the 
inductor current) controlled at a frequency that is the double of the switching frequency, i.e., with similar characteristics to a conventional interleaved converter; (ii) The B3L dc-dc converter operates with three-levels (different from the conventional two-level dc-dc half-bridge), depending on the output voltage, representing an interesting feature for improving efficiency, as the voltage applied to each switching device is reduced to half. The validation, performed by meticulous computational models and by laboratory experimental results, demonstrates the features of the $\mathrm{B} 3 \mathrm{~L}$ dc-dc converter when used as dc-dc power stage in on-board or off-board EV chargers. After introducing the main topic of the paper and highlight the main features of the B3L dc-dc converter, section II presents a framework with on-board or off-board EV chargers, section III presents the proposed control strategy and establishes a comparison with the interleaved converter, section IV focus on the experimental validation, while section $\mathrm{V}$ finalizes the paper.

\section{THREE-LEVEL DC-DC CONVERTER: INTRODUCTION}

The framework of the B3L dc-dc converter with the on-board or off-board EV chargers was introduced in Fig. 1. In Fig. 1(a) is presented a solution of an on-board charger based on a non-isolated system, where the $\mathrm{B} 3 \mathrm{~L}$ dc-dc converter is used as a power stage between the ac-dc converter (single-phase power stage) and the batteries. Also for a solution of an on-board charger, but based on an isolated system, Fig. 1(b) presents the B3L dc-dc converter used as a power stage between the galvanic isolated dc-dc converter and the batteries. In Fig. 2(a) is presented a solution of an off-board charger based on a non-isolated system, where the B3L dc-dc converter is used as a power stage between the ac-dc converter (three-phase power stage) and the batteries. Also for a solution of an off-board charger, but based on an isolated system, Fig. 2(b) presents the B3L dc-dc converter used as a power stage between the galvanic isolated dc-dc converter and the batteries. The B3L dc-dc converter is shown in Fig. 3(a). Since the current of the inductor is controlled with the double of the switching frequency, a comparison is established with the conventional interleaved converter (cf. Fig. 3(b)). It is relevant to mention that the interleaved converter can be used as dc-dc stage according to Fig. 1 and Fig. 2. As in Fig. 3(a), the B3L dc-dc converter requires a split dc-link and four switching devices for obtaining a bidirectional and three-level operation. The switching devices are controlled in couples, according to the operating functionality, i.e., in buck-mode (IGBTs $s_{1}$ and $s_{4}$ ) or in boost-mode (IGBTs $s_{2}$ and $s_{4}$ ) mode. Independently of the output voltage level, which defines the voltage level where the converter operates, the IGBTs of each set $\left(s_{1}, s_{4}\right.$ and $\left.s_{2}, s_{3}\right)$ are controlled with a PWM based on two carriers with a phase-shift of 180 degrees (cf. section III). Table I summarizes the valid states of the bidirectional three-level dc-dc converter, according to the operating modes. Fig. 4 illustrates the relationship of duty-cycle with normalized current ripple on the inductor $\left(i_{d c}\right)$, for both the buck-mode and boost-mode. As it turns out, for the buck-mode, the duty-cycle ratio between 0 and $50 \%$ is symmetrical to the ratio between $50 \%$ to $100 \%$. The current ripple has a bigger value when the duty-cycle is close to $25 \%$ and $75 \%$, and a lower value when the duty-cycle is close

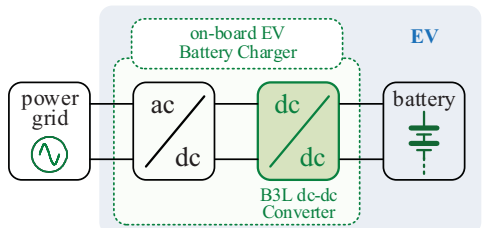

(a)

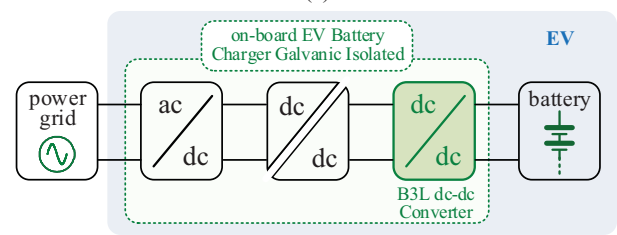

(b)

Fig. 1. Integration of the B3L dc-dc converter in on-board EV battery chargers: (a) Galvanic non-isolated system; (b) Galvanic isolated system.

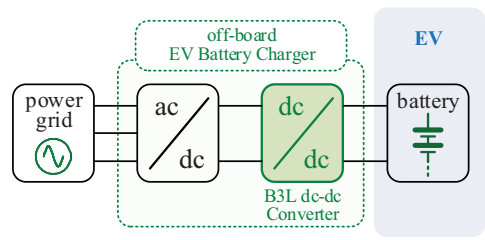

(a)

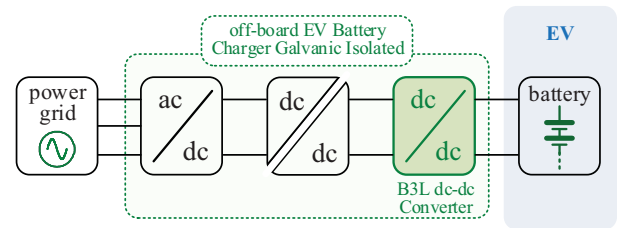

(b)

Fig. 2. Integration of the B3L dc-dc converter in off-board EV battery chargers: (a) Galvanic non-isolated system; (b) Galvanic isolated system.

to $0 \%, 50 \%$ and $100 \%$. For the boost-mode, the situation is quite different, with the current ripple being almost always greater between $50 \%$ and $100 \%$, when compared with the range between 0 and $50 \%$. The ripple assumes lower values when the duty-cycle is close to 0 and $50 \%$, and bigger values when close to $100 \%$. With the objective to demonstrate the operation of the B3L dc-dc converter, when compared with the interleaved dc-dc converter, a set of simulations were carried-out. For simplicity, it was considered an on-board charger in buck-mode as an example, however, the principle of operation can be applied also for off-board chargers. In the dc-link, a voltage of $400 \mathrm{~V}$ (divided into $200 \mathrm{~V}$ symmetrical voltages) was considered. In the battery-side, an inductor of $1 \mathrm{mH}$ and a capacitor of $100 \mu \mathrm{F}$ were used. In both cases, $40 \mathrm{kHz}$ (sampling) and $20 \mathrm{kHz}$ (switching) were used. Initially, a battery-side voltage of $100 \mathrm{~V}$ was considered (which is smaller than $200 \mathrm{~V}$, half of the dc-link).

In Fig. 5 is presented a result that shows the current of the B3L dc-dc converter $\left(i_{d c} B 3 L\right)$ compared to the current of the interleaved converter $\left(i_{d c} B I\right)$, as well as the voltage of both converters $\left(v_{x z}\right.$ for the B3$\overline{\mathrm{L}}$ dc-dc converter, and $v_{x z}$ and $v_{y z}$ for the interleaved converter). Considering the same operating conditions, it is verified that the resultant frequency is the same for both converters, but the current ripple value of the $\mathrm{B} 3 \mathrm{~L}$ $\mathrm{dc}$-dc converter $(0.6 \mathrm{~A})$ is much lower than the current ripple of the interleaved converter $(2.4 \mathrm{~A})$. In the case of the B3L dc-dc converter, the voltage produced by the converter varies 


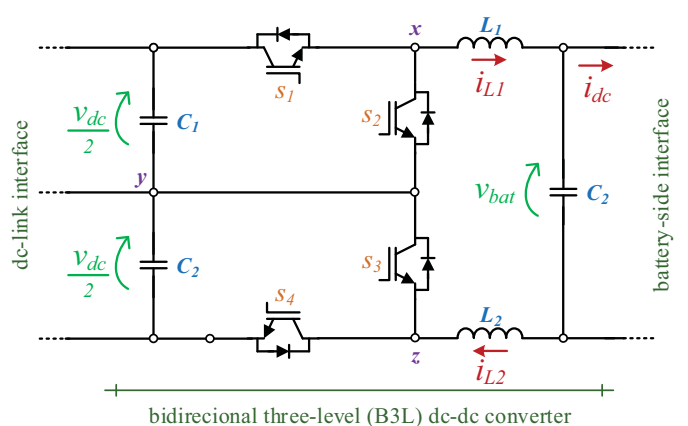

(a)

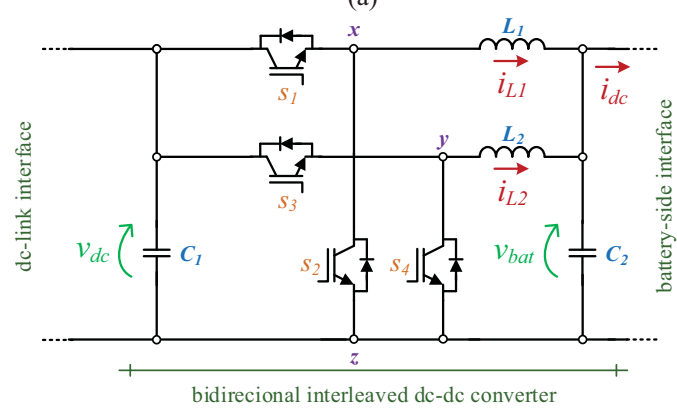

(b)

Fig. 3. Topologies of power converters: (a) B3L dc-dc converter; (b) Bidirectional interleaved dc-dc converter.

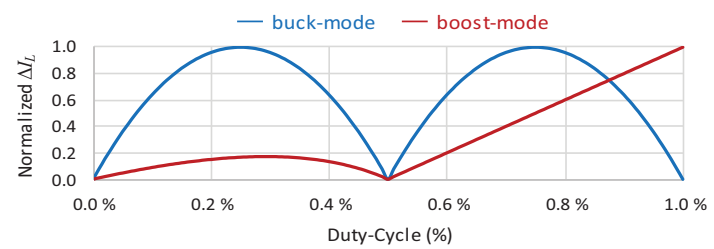

Fig. 4. B3L dc-dc converter: Relationship of duty-cycle with normalized current ripple on the inductor $\left(i_{d c}\right)$ for the buck-mode and for the boost-mode.

between 0 and $v_{d c} / 2$, whereas in the case of the interleaved converter the voltage varies between 0 and $v_{d c}$. Similar to the previous case, the same variables are shown in Fig. 6 , but a battery-side voltage of $300 \mathrm{~V}$ was considered, which is bigger than $200 \mathrm{~V}$, half of the dc-link. Once again, considering the same operating conditions, it is verified that the frequency is the same for both converters and the current ripple variation is similar to the previous case (the B3L dc-dc converter presents better results of current ripple). For this case of operation, the voltage of the B3L dc-dc converter varies between $v_{d c} / 2$ and $v_{d c}$, whereas in the case of the interleaved converter the voltage continues to vary between 0 and $v_{d c}$. The most important difference between the B3L dc-dc converter and the interleaved $\mathrm{dc}-\mathrm{dc}$ converter is the voltage that each switching device should support. Also in this aspect, the B3L dc-dc converter behaves better for any condition of operation (buck-mode or boost-mode with the battery-side voltage bigger or smaller than half of the dc-link voltage). For the B3L dc-dc converter, each switching device must support a maximum voltage of $v_{d c} / 2$, which is half of the voltage that each switching device of the interleaved dc-dc converter must support (i.e., a voltage of $v_{d c}$ ).

\section{Three-LeVel Converter: Control Strategy}

The adopted PWM strategy is explained in this section, and it is defined according to the current control technique. It is important to note that the control strategy is developed for all

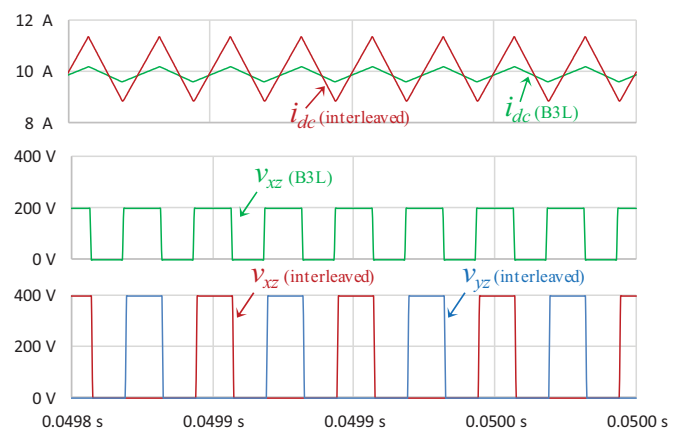

Fig. 5. Comparison between the B3L dc-dc converter and the interleaved converter for a current reference of $10 \mathrm{~A}$ and for a battery-side voltage of $100 \mathrm{~V}$ (a value less than half the value of the dc link voltage).

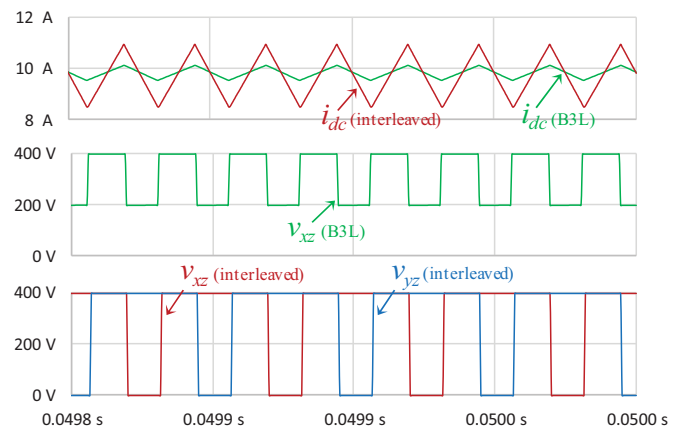

Fig. 6. Comparison between the B3L dc-dc converter and the interleaved converter for a current reference of $10 \mathrm{~A}$ and for a battery-side voltage of $300 \mathrm{~V}$ (a value greater than half the value of the dc link voltage).

the operating modes (cf. Table I). The current in each inductor has a ripple, whose frequency corresponds to the double of the switching frequency (cf. Fig. 3). The battery-side of the converter is controlled with current or voltage. However, since the final application is an on-board or an off-board charger, the control with current feedback is most relevant. In fact, the algorithm constant-current constant-voltage can also be applied for both cases, depending of the battery technology. With a current feedback, the battery charging current is controlled for a constant value, while the battery voltage increases until the maximum admissible by the battery (representing about $80 \%$ of the charging process). In the scope of this paper, fixed frequency control and switching were implemented. Analyzing Fig. 3(a), during the charging process, the relation between voltages can be established as:

$$
\begin{aligned}
& v_{x y}-v_{L 1}-v_{L 2}-v_{b a t}=0, \\
& v_{y z}-v_{L 1}-v_{L 2}-v_{b a t}=0,
\end{aligned}
$$

where $v_{x y}$ and $v_{y z}$ corresponds to the voltages that the converter can produce, while $v_{L 1}$ and $v_{L 2}$ correspond to the voltages in $L_{1}$ and $L_{2}$, and $v_{\text {bat }}$ is the battery-side voltage. As the current in $L_{1}$ is the same as in $L_{2}$, yields:

$$
\begin{aligned}
& \frac{-d i_{L 1}}{d t}\left(L_{1}+L_{2}\right)-v_{b a t}+v_{x y}=0, \\
& \frac{-d i_{L 2}}{d t}\left(L_{1}+L_{2}\right)-v_{b a t}+v_{y z}=0 .
\end{aligned}
$$

Applying the forward Euler method, the discretized equations for the digital algorithm are: 


$$
\begin{aligned}
& \left(L_{1}+L_{2}\right)\left(i_{L 1}[k+1]-i_{L 1}[k]\right) T_{s}^{-1}+v_{b a t}-v_{x y}[k]=0, \\
& \left(L_{1}+L_{2}\right)\left(i_{L 1}[k+1]-i_{L 1}[k]\right) T_{s}^{-1}+v_{b a t}-v_{y z}[k]=0,
\end{aligned}
$$

In these equations, the reference of current is used as a substitution of $i_{L I}[k+1]$ and $i_{L 2}[k+1]$. The value for the reference of current is not established by the current control algorithm. It is an input variable obtained from the battery management system (BMS), whose analysis is out of the scope of this paper [29]. As the objective is to control the current with the double of the switching frequency, the PWM should be prepared for that, therefore, two carriers shifted 180 degrees are used in the PWM control. From equations (5) and (6), the variables $v_{x y}[k]$ and $v_{y z}[k]$ are the references that are compared with the PWM carriers in order to obtain the gate pulse patterns, respectively, for the IGBTs $s_{1}$ and $s_{4}$. Analyzing Fig. 3(a) during the discharging process, the relation between voltages is established as:

$$
\begin{aligned}
& \frac{-d i_{L 1}}{d t}\left(L_{1}+L_{2}\right)+v_{b a t}-v_{x y}=0, \\
& \frac{-d i_{L 2}}{d t}\left(L_{1}+L_{2}\right)+v_{b a t}-v_{y z}=0 .
\end{aligned}
$$

Also applying the Euler method results in:

$$
\begin{aligned}
& \left(L_{1}+L_{2}\right)\left(i_{L 1}[k+1]-i_{L 1}[k]\right) T_{s}^{-1}-v_{b a t}+v_{x y}[k]=0, \\
& \left(L_{1}+L_{2}\right)\left(i_{L 1}[k+1]-i_{L 1}[k]\right) T_{s}^{-1}-v_{b a t}+v_{y z}[k]=0,
\end{aligned}
$$

Once again, two carriers shifted 180 degrees are used in the PWM control in this operation mode. From equations (9) and (10), the variables $v_{x y}[k]$ and $v_{y z}[k]$ are the references that are compared with the PWM carriers in order to obtain the gate pulse patterns, respectively, for the IGBTs $s_{2}$ and $s_{3}$.

\section{ThreE-LeVEl CONVERTER: EXPERIMENTAL VALIDATION}

The photography in Fig. 7 shows, respectively, the workbench of the on-board charger and the workbench of the off-board charger. The on-board prototype was connected to the single-phase power grid of $230 \mathrm{~V}-50 \mathrm{~Hz}$ and the off-board prototype to the three-phase power grid of $400 \mathrm{~V}-50 \mathrm{~Hz}$. The on-board prototype is based on the structure presented in Fig. 1(a) and the off-board prototype is based on Fig. 2(b). The experimental results were obtained for a power of $3.6 \mathrm{~kW}$, in the case of the on-board prototype, and for a power of $10 \mathrm{~kW}$, in the case of the off-board prototype. In both cases, $40 \mathrm{kHz}$ (sampling) and $20 \mathrm{kHz}$ (switching) were used. A Yokogawa digital oscilloscope was used to register the results, as well as a CP35 PROSyS current probe. It is important to note that, in all the obtained results, the peaks that occur in the voltage produced by the converter $\left(v_{x y}\right)$ are not real, but a cause of the oscilloscope (without any type of digital filter) and the voltage probes used. Fig. 8 shows an experimental result of the on-board during the battery charging process. During this process, the B3L dc-dc converter operates in buck-mode with the power flowing from the dc-link to the battery-side and it is possible to measure and verify the current on the battery-side $\left(i_{L 1}\right)$ and the voltage produced by the converter $\left(v_{x y}\right)$. By means of this result, it is possible to verify that $v_{x y}$ has three-levels,

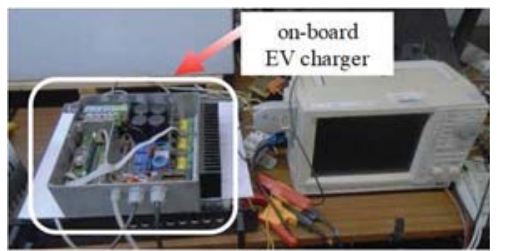

(a)

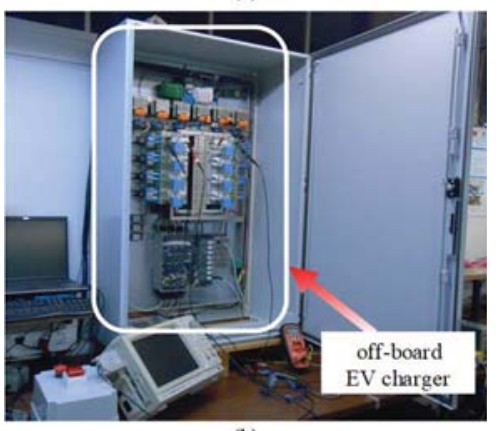

Fig. 7. Laboratory workbench showing the: (a) On-board EV battery charger; (b) Off-board EV battery charger.

according to the dc-link voltages. These levels are set according to the battery-side voltage. During case \#1, the charging process has not yet started, so the current is at zero level, as well as the voltage produced by the converter. During case \#2, the battery-side voltage is smaller than half of the dc-link voltage $\left(v_{b a t}<v_{d c} / 2\right)$, in which case, the current increases progressively until a fixed value of $4 \mathrm{~A}$. Throughout case \# 2 the voltage produced by the converter varies between 0 and $v_{d c} / 2$. Subsequently, in case \#3, the current increases again progressively until reaching a fixed value of $10 \mathrm{~A}$. As in this case the battery-side voltage increases to be superior to half of the dc-link voltage, the voltage of the converter varies between $v_{d c} / 2$ and $v_{d c}$. This result proves the operation of the converter with the three-levels, in which case the voltage produced by the converter has a maximum variation of $v_{d c} / 2$. Fig. 9 presents an experimental result of the on-board converter during the boost-mode considering a battery-side voltage almost equal to half of the dc-link voltage (this was considered as an example, different from the voltages in buck-mode, since other voltages can be considered). In this result, besides the current on the battery-side $\left(i_{d c}\right)$ and the voltage produced by the converter $\left(v_{x z}\right)$ graphs, are also represented the gate-emitter voltages in the IGBTs $s_{2}$ and $s_{3}$. As the battery-side voltage is almost equal to half of the dc-link voltage, the voltage produced by the converter has about a fixed value of $v_{d c} / 2$, which corresponds to a duty-cycle about of 50\% in each IGBT, as it is shown in this experimental result. Fig. 10 shows an experimental result of the off-board charger during the battery charging process (i.e., the B3L dc-dc converter operates in buck-mode with the power following from the dc-link to the battery), where it is possible to verify the current on the battery-side $\left(i_{d c}\right)$ and the voltage produced by the converter $\left(v_{x z}\right)$. Analogously to the on-board charger, it turns out that the voltage produced by the converter has all the three-levels. In this case, it was considered a progressive increase of the current until reaching a constant value of $30 \mathrm{~A}$. During this progressive increase, the voltage produced by the converter changes the levels, corresponding to a change of the battery-side voltage. In case \#1, the voltage produced by the converter varies between 0 and $v_{d c} / 2$, while in 


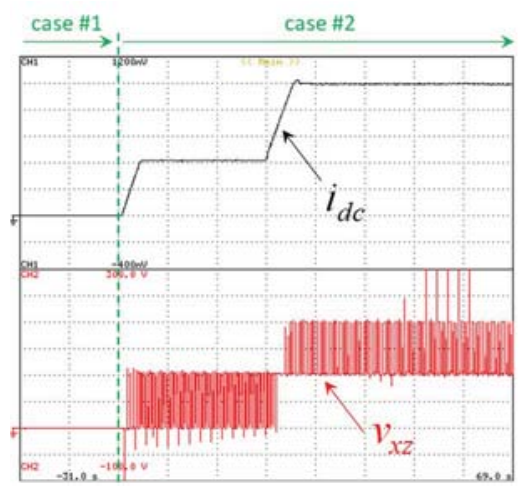

Fig. 8. Experimental results of the on-board EV charger (buck-mode): Current $\left(i_{d c}: 2 \mathrm{~A} / \mathrm{div}\right)$; Voltage produced by the converter $\left(v_{x y}: 50 \mathrm{~V} / \mathrm{div}\right)$.

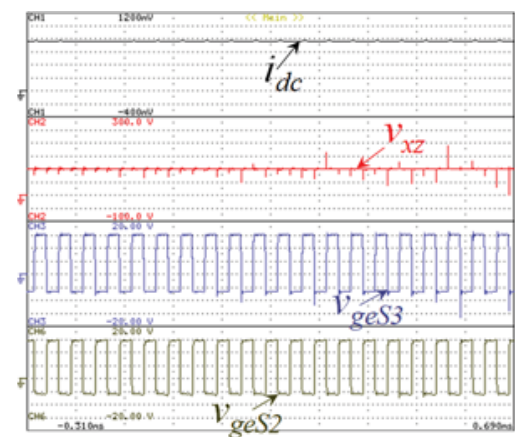

Fig. 9. Experimental results of the on-board EV charger (boost-mode with a battery-side voltage almost equal to half of the dc-link voltage): Current $\left(i_{d c}: 2 \mathrm{~A} / \mathrm{div}\right)$; Voltage of the converter $\left(v_{x z}: 50 \mathrm{~V} / \mathrm{div}\right)$; Gate-emitter voltage of the IGBTs $s_{1}\left(v_{\text {gesl }}: 5 \mathrm{~V} / \mathrm{div}\right)$ and $s_{4}\left(v_{\text {ges }}: 5 \mathrm{~V} / \mathrm{div}\right)$

case \#2 varies between $v_{d c} / 2$ and $v_{d c}$. In order to depict the switching frequency and the resulting frequency, Fig. 11 shows the voltage produced by the converter $\left(v_{x z}\right)$ and the gate-emitter voltage in the IGBTs $s_{1}$ and $s_{4}$. This result was obtained for a current of $10 \mathrm{~A}$ corresponding to a battery-side voltage lower than $v_{d c} / 2$, i.e., the voltage produced by the converter varies between 0 and $v_{d c} / 2$. For this reason, it is noted that the IGBT switching does not occur simultaneously, i.e., the duty-cycle applied to each IGBT is smaller than $50 \%$. This result clearly shows that the resulting frequency, i.e., the frequency of the converter voltage, corresponds to twice the switching frequency of each IGBT (which is equal for both IGBTs). As the duty-cycle of each IGBT is about $25 \%$, the duty-cycle of the voltage produced by the converter is about $50 \%$.

With these results, it is validated that the converter has an operating principle similar to the interleaved converter, but with half of the voltage produced by the converter (therefore, half of the voltage stress on each IGBT). Similarly to the previous case, but for a situation where the battery-side voltage is bigger than $v_{d c} / 2$, Fig. 12 shows the voltage produced by the converter $\left(v_{x z}\right)$ and the gate-emitter voltage in the IGBTs $s_{l}$ and $s_{4}$. This result was obtained for a current of $30 \mathrm{~A}$, corresponding to a voltage variation between $v_{d c} / 2$ and $v_{d c}$. In this situation, it is seen that the switching of the IGBTs occur simultaneously, i.e., the duty-cycle applied to each IGBT is greater than $50 \%$. Once again, it is verified that the frequency of the voltage produced by the converter corresponds to twice of the switching frequency of each IGBT. As the duty-cycle of

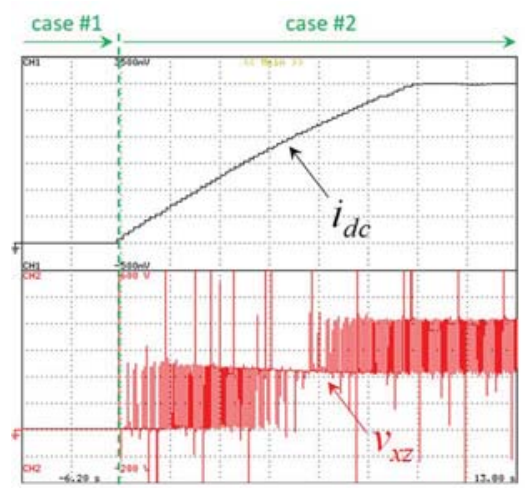

Fig. 10. Experimental results of the off-board EV charger (buck-mode): Current $\left(i_{d c}: 5 \mathrm{~A} / \mathrm{div}\right)$; Voltage of the converter $\left(v_{x y}: 100 \mathrm{~V} / \mathrm{div}\right)$.

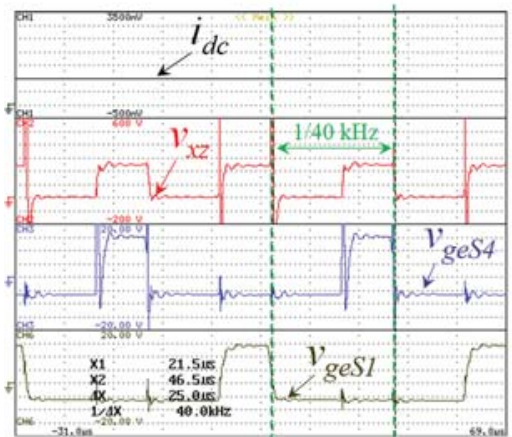

Fig. 11. Experimental results of the off-board EV charger (buck-mode with a battery-side voltage smaller than half of the dc-link voltage): Current $\left(i_{d c}: 5 \mathrm{~A} / \mathrm{div}\right)$; Voltage of the converter $\left(v_{x z}: 100 \mathrm{~V} / \mathrm{div}\right)$; Gate-emitter voltage of the IGBTs $s_{1}\left(v_{\text {gesi }}: 5 \mathrm{~V} / \mathrm{div}\right)$ and $s_{4}\left(v_{\text {ges } 4}: 5 \mathrm{~V} / \mathrm{div}\right)$.

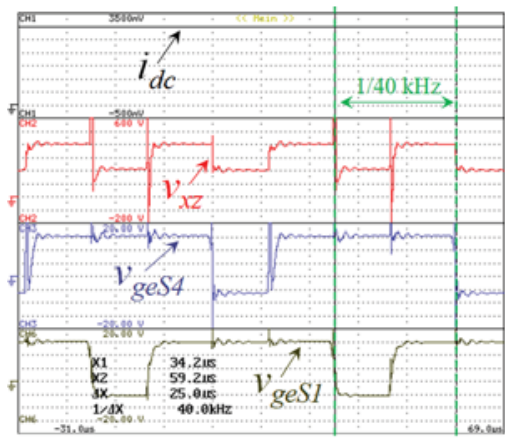

Fig. 12. Experimental results of the off-board EV charger (buck-mode with a battery-side voltage greater than half of the dc-link voltage): Current $\left(i_{d c}: 5 \mathrm{~A} / \mathrm{div}\right)$; Voltage of the converter $\left(v_{x z}: 100 \mathrm{~V} / \mathrm{div}\right)$; Gate-emitter voltage of the IGBTs $s_{1}\left(v_{\text {gesi }}: 5 \mathrm{~V} / \mathrm{div}\right)$ and $s_{4}\left(v_{\text {gesl }}: 5 \mathrm{~V} / \mathrm{div}\right)$.

each IGBT is about $75 \%$, the duty-cycle of the voltage produced by the converter is about $50 \%$.

\section{Conclusions}

In this paper, a bidirectional three-level (B3L) dc-dc converter, with its topology and control technique, is presented for electric mobility applications. Due to its versatility, it can be used in on-board or off-board EV battery chargers. When compared with conventional solutions, the B3L dc-dc converter presents the advantages of operating with three-levels and having the variables controlled with the double of the switching frequency. Since the B3L dc-dc converter allows bidirectional operation, a set of experimental results were obtained during 
the buck-mode and boost-mode, and considering the battery-side voltage greater than and less than half the DC bus voltage. Such experimental verification was carried-out using two developed laboratory prototypes, an on-board charger and an off-board charger.

\section{ACKNOWLEDGMENT}

This work has been supported by national funds through FCT - Fundação para a Ciência e Tecnologia within the Project Scope: UID/CEC/00319/2019. This work has been supported by FCT Project newERA4GRIDs PTDC/EEI-EEE/30283/2017, and by the FCT Project DAIPESEV PTDC/EEIEEE/30382/2017.

\section{REFERENCES}

[1] A. P. Sakis Meliopoulos, George Cokkinides, Renke Huang, Evangelos Farantatos, Sungyun Choi, Yonghee Lee, Xuebei Yu, "Smart Grid Technologies for Autonomous Operation and Control," IEEE Trans. Smart Grid, vol.2, no.1, pp.1-10, Mar. 2011.

[2] Vehbi C. Gungor, Dilan Sahin, Taskin Kocak, Salih Ergut, Concettina Buccella, Carlo Cecati, Gerhard P. Hancke, "Smart Grid and Smart Homes - Key Players and Pilot Projects," IEEE Ind. Electron. Mag., vol.6, pp.18-34, Dec. 2012.

[3] Xinghuo Yu, Carlo Cecati, Tharam Dillon, M. Gody Simoes, "The New Frontier of Smart Grids: An Industrial Electronics Perspective," IEEE Ind. Electron. Mag. vol.5, no.3, pp.49-63, Sept. 2011.

[4] C. C. Chan, "The State of the Art of Electric, Hybrid, and Fuel Cell Vehicles,” Proc. IEEE, vol.95, no.4, pp.704-718, Apr. 2007.

[5] Vitor Monteiro, Bruno Exposto, Joao C. Ferreira, Joao L. Afonso, "Improved Vehicle-to-Home (iV2H) Operation Mode: Experimental Analysis of the Electric Vehicle as Off-Line UPS," IEEE Transactions on Smart Grid, vol.8, no.6, pp.2702-2711, Nov. 2017.

[6] Alireza Khaligh, Zhihao Li, "Battery, Ultracapacitor, Fuel Cell, and Hybrid Energy Storage Systems for Electric, Hybrid Electric, Fuel Cell, and Plug-In Hybrid Electric Vehicles: State of the Art," IEEE Trans. Veh. Technol., vol.59, no.6, pp.2806-2814, July 2010.

[7] C. C. Chan, Alain Bouscayrol, Keyu Chen, "Electric, Hybrid, and FuelCell Vehicles: Architectures and Modeling," IEEE Trans. Veh. Technol., vol.59, no.2, pp.589-598, Feb. 2010.

[8] Wencong Su, Habiballah Rahimi-Eichi, Wente Zeng, Mo-Yuen Chow, "A Survey on the Electrification of Transportation in a Smart Grid Environment," IEEE Trans. Ind. Informat., vol.8, no.1, pp.1-10, Feb. 2012.

[9] Joao A. Pecas Lopes, Filipe Soares, Pedro M. Rocha Almeida, "Integration of Electric Vehicles in the Electric Power Systems," Proc. IEEE, vol.99, no.1, pp.168-183, Jan. 2011.

[10] Changsong Chen, Shanxu Duan, "Optimal Integration of Plug-In Hybrid Electric Vehicles in Microgrids," IEEE Trans. Ind. Informat., vol.10, no.3, pp.1917-1926, Aug. 2014.

[11] Iban Junquera Martinez, Javier Garcia-Villalobos, Inmaculada Zamora, Pablo Eguia, "Energy Management of Micro Renewable Energy Source and Electric Vehicles at Home Level ," SPRINGER Journal of Modern Power Systems and Clean Energy, vol.5, no.6, pp.979-990, Nov. 2017.

[12] Chenrui Jin, Jian Tang, Prasanta Ghosh, "Optimizing Electric Vehicle Charging: A Customer's Perspective," IEEE Trans. Veh. Technol., vol.62, no.7, pp.2919-2927, Sept. 2013.

[13] Ahmed Yousuf Saber, Ganesh Kumar Venayagamoorthy, "Plug-in Vehicles and Renewable Energy Sources for Cost and Emission Reductions,'IEEE Trans. Ind. Electron., vol.58, no.4, pp.1229-1238, Apr. 2011.

[14] Jorge E. Hernandez, Frank Kreikebaum, Deepak Divan, "Flexible Electric Vehicle (EV) Charging to Meet Renewable Portfolio Standard (RPS) Mandates and Minimize Green House Gas Emissions," IEEE ECCE Energy Conversion Congress and Exposition, Atlanta USA, pp.4270-4277, Sept. 2010.

[15] Willett Kempton, Jasna Tomic, "Vehicle-to-Grid Power Implementation: From Stabilizing the Grid to Supporting Large-Scale Renewable Energy," ELSEVIER Journal of Power Sources, vol.144, pp.280-294, Apr. 2015.

[16] Jun Hua Zhao, Fushuan Wen, Zhao Yang Dong, Yusheng Xue, Kit Po Wong, "Optimal Dispatch of Electric Vehicles and Wind Power Using Enhanced Particle Swarm Optimization,” IEEE Trans. Ind. Informat. vol.8, no.4, pp.889-899, Nov. 2012.

[17] Wayes Tushar, Chau Yuen, Shisheng Huang, David B. Smith, H. Vincent Poor, "Cost Minimization of Charging Stations With Photovoltaics: An Approach with EV Classification," IEEE Trans. Intell. Transp. Syst., vol.17, no.1, pp.156-169, Jan. 2016.

[18] Mosaddek Hossain Kamal Tushar, AdelW. Zeineddine, Chadi Assi, "Demand-Side Management by Regulating Charging and Discharging of the EV, ESS, and Utilizing Renewable Energy," IEEE Trans. Ind. Informat., vol.14, no.1, pp.117-126, Jan. 2018.

[19] Rafael Leite, Joao L. Afonso, Vitor Monteiro, “A Novel Multilevel Bidirectional Topology for On-Board EV Battery Chargers in Smart Grids," MDPI Energies, vol.11, no.12, pp.1-21, Dec. 2018.

[20] Vitor Monteiro, Jose A. Afonso, Joao C. Ferreira, Joao L. Afonso, "Vehicle Electrification: New Challenges and Opportunities for Smart Grids," MDPI Energies, vol.12, no.1, pp.1-20, Dec. 2018.

[21] Vitor Monteiro, Joao C. Ferreira, Andres A. Nogueiras Melendez, Joao L. Afonso, "Model Predictive Control Applied to an Improved FiveLevel Bidirectional Converter," IEEE Trans. Ind. Electron., vol.63, no.9, pp.5879-5890, Sept. 2016.

[22] Vitor Monteiro, J. G. Pinto, Joao L. Afonso, "Experimental Validation of a Three-Port Integrated Topology to Interface Electric Vehicles and Renewables with the Electrical Grid”, IEEE Trans. Ind. Informat., vol.14, no.6, pp 2364-2374, June 2018.

[23] Gustavo Gamboa, Christopher Hamilton, Ross Kerley, Sean Elmes, Andres Arias, John Shen, Issa Batarseh, "Control Strategy of a MultiPort, Grid Connected, Direct-DC PV Charging Station for Plug-in Electric Vehicles," IEEE Energy Conversion Congress and Exposition, pp.1173-1177, Sept. 2010.

[24] Christopher Hamilton, Gustavo Gamboa, John Elmes, Ross Kerley, Andres Arias, Michael Pepper, John Shen, Issa Batarseh, "System Architecture of a Modular Direct-DC PV Charging Station for Plug-in Electric Vehicles," IEEE IECON Annual Conference on Industrial Electronics Society, pp.2516-2520, Nov. 2010.

[25] Joshua Traube, Fenglog Lu, Dragan Maksimovic, "Photovoltaic Power System with Integrated Electric Vehicle DC Charger and Enhanced Grid Support," EPE/PEMC International Power Electronics and Motion Control Conference, pp.1-5, Sept. 2012.

[26] Taesik Park, Taehyung Kim, "Novel Energy Conversion System Based on a Multimode Single-Leg Power Converter," IEEE Trans. Power Electron., vol.28, no.1, pp.213-220, Jan. 2013.

[27] Gustavo Gamboa, Christopher Hamilton, Ross Kerley, Sean Elmes, Andres Arias, John Shen, Issa Batarseh, "Control Strategy of a MultiPort, Grid Connected, Direct-DC PV Charging Station for Plug-in Electric Vehicles," IEEE Energy Conversion Congress and Exposition, pp.1173-1177, Sept. 2010.

[28] Vitor Monteiro, Joao C. Ferreira, Andres A. Nogueiras Melendez, Carlos Couto, Joao L. Afonso, "Experimental Validation of a Novel Architecture Based on a Dual-Stage Converter for Off-Board Fast Battery Chargers of Electric Vehicles," IEEE Trans. Veh. Tech., vol.67, no.2, pp.1000-1011, Feb. 2018.

[29] Vitor Monteiro, J. G. Pinto, Bruno Exposto, Joao C. Ferreira, Joao L. Afonso, "Smart Charging Management for Electric Vehicle Battery Chargers," IEEE VPPC Vehicle Power and Propulsion Conference, pp.1-5, Oct. 2014. 